Brazilian Journal

of Chemical

ISSN 0104-6632

Engineering

\title{
RHEOLOGICAL AND MORPHOLOGICAL CHARACTERIZATION OF Streptomyces olindensis GROWING IN BATCH AND FED-BATCH FERMENTATIONS
}

\author{
C. R. D. Pamboukian and M. C. R. Facciotti* \\ Department of Chemical Engineering, Escola Politécnica da Universidade de São Paulo, \\ Fax : +(55) (11) 3031-3020, P.O. Box. 61548, 05424-970, São Paulo - SP, Brazil \\ E-mail: mcrfacci@usp.br)
}

(Received: July 16, 2003 ; Accepted: October 5, 2004)

\begin{abstract}
Mathematical correlations between rheological properties of the fermentation broth (consistency index, K, and flow behavior index, $\mathrm{n}$ ), biomass concentration (X) and average clump dimension (D) of Streptomyces olindensis in bioreactor cultivations were obtained, during batch and fed-batch processes. Two types of correlations were compared: the first considered the influence of only biomass concentration (X) on rheological properties ( $\mathrm{K}$ and $\mathrm{n}$ ), the second considered the influence of both biomass concentration (X) and morphology (average clump dimension, D) on rheological properties. Clump dimension was assessed by image analysis. Clumps were shown to be the major morphological class during all runs. Incorporation of the morphological parameter in the model improved the capacity to predict the experimental values of the consistency index $(\mathrm{K})$.

Key words: Clump dimension; Image analysis; Morphology; Rheology; Streptomyces.
\end{abstract}

\section{INTRODUCTION}

Most commercial secondary metabolites, such as antibiotics, pigments and toxins, are produced by filamentous microorganisms in submerged cultures. Streptomyces spp. is one of the most important microorganisms used in antibiotic production, and since it is a filamentous microorganism, rheology and morphology of the mycelial broth affect mixing, oxygen transfer and, consequently, antibiotic production, as pointed by many authors (Badino Jr et al., 1999; Riley et al., 2000). Particularly, Streptomyces olindensis is a strain producer of retamycin, an anthracycline antibiotic complex with potent antitumour activity, similar to daunorubicin and doxorubicin, showing positive results in the treatment of human leukaemia (Bieber et al., 1989). A large number of factors, such as biomass concentration and morphological characteristics, can influence rheological properties of the fermentation broth (Allen and Robinson, 1990; Ruohang and Webb, 1995). Many authors have proposed correlations between cell concentration (X) and consistency index $(\mathrm{K})$, calculated from the powerlaw model $\left(\tau=\mathrm{K} . \gamma^{\mathrm{n}}\right)$ (Queiroz et al., 1997; Badino $\mathrm{Jr}$ et al., 1999). Besides, morphology plays an important role in the production of metabolites and influences the rheological properties of the fermentation broth (Pamboukian et al., 1998; Yang et al., 1996). Thus, many authors have proposed the introduction of morphological parameters into the correlation between the consistency index $(\mathrm{K})$ and biomass concentration (X) (Olsvik et al., 1993; Riley et al., 2000). Olsvik et al. (1993) used shape factors (circularity and roughness) to represent morphology in the models for predicting rheological properties of

*To whom correspondence should be addressed 
the fermentation broth. Riley et al. (2000), in a recent work, used projected area and average clump dimension to represent the microorganism morphology in a rheological model of Penicillium chrisogenum cultivations. Regarding morphology, previous works showed that the production of retamycin is favoured by the growth in the form of clumps (Pamboukian and Facciotti, 2004a; Pamboukian and Facciotti, 2004b), similarly to other antibiotics (Yang et al., 1996).

Particularly in Streptomyces fermentations, there are few works focusing rheological properties and correlating both rheology and morphology in the fermentations. Thus, this paper proposes mathematical correlations between biomass, clump dimension and both consistency index and flow behavior index, in batch and fed-batch cultivations of Streptomyces olindensis. Morphological characteristics (average clump dimension) of the strain were evaluated by image analysis.

\section{MATERIALS AND METHODS}

\section{Microorganism}

A mutant strain of Streptomyces olindensis ICB20 was supplied by Laboratório de Genética de Microrganismos/Instituto de Ciências Biomédicas/ Universidade de São Paulo. The cells were stored in cryotubes containing glycerol $20 \%$, at $-20^{\circ} \mathrm{C}$ (Guimarães, 2000).

\section{Culture Medium}

The culture medium contained the following nutrients (Furlan, 1997): glucose $(10.0 \mathrm{~g} / \mathrm{L})$, yeast extract $(5.0 \mathrm{~g} / \mathrm{L})$, tris(hydroxymethyl)-aminometan $(3.09 \mathrm{~g} / \mathrm{L})$, casein hydrolysate $(0.10 \mathrm{~g} / \mathrm{L}), \mathrm{K}_{2} \mathrm{SO}_{4}$ $(0.25 \mathrm{~g} / \mathrm{L})$ and $\mathrm{MgCl}_{2} \cdot 6 \mathrm{H}_{2} \mathrm{O}(10.12 \mathrm{~g} / \mathrm{L})$. The $\mathrm{pH}$ was adjusted to 7.0 using $\mathrm{HCl} 2 \mathrm{~N}$. After medium sterilization, the following sterile solutions were added (for $250 \mathrm{~mL}$ of culture medium): $\mathrm{KH}_{2} \mathrm{PO}_{4} 0.5$ $\% \mathrm{w} / \mathrm{v}(2.5 \mathrm{~mL}), \mathrm{CaCl}_{2} 5 \mathrm{M}(1.0 \mathrm{~mL})$ and $0.5 \mathrm{~mL}$ of a trace element solution $\left(40 \mathrm{mg} \mathrm{ZnCl}_{2}, 200 \mathrm{mg}\right.$ $\mathrm{FeCl}_{3} \cdot 6 \mathrm{H}_{2} \mathrm{O}, 10 \mathrm{mg}\left(\mathrm{NH}_{4}\right)_{6} \mathrm{Mo}_{7} \mathrm{O}_{24} \cdot 4 \mathrm{H}_{2} \mathrm{O}, 10 \mathrm{mg}$ $\mathrm{CuCl}_{2} \cdot 2 \mathrm{H}_{2} \mathrm{O}, \quad 10 \mathrm{mg} \quad \mathrm{MnCl}_{2} \cdot 4 \mathrm{H}_{2} \mathrm{O}, 10 \mathrm{mg}$ $\mathrm{Na}_{2} \mathrm{~B}_{4} \mathrm{O}_{7} \cdot 10 \mathrm{H}_{2} \mathrm{O}$ in $1000 \mathrm{~mL}$ of distilled water).

\section{Culture Conditions}

Eight batch runs were performed in a 5-L New Brunswick Bioflo fermenter under the following conditions: working volume $=4 \mathrm{~L}$; agitation rate $=$
$500 \mathrm{rev} / \mathrm{min}$; air flow rate $=4 \mathrm{~L} / \mathrm{min} ; \mathrm{pH}=7.0$ and temperature $=30^{\circ} \mathrm{C}$. The fermenter was provided with two flat blade turbine disk impellers, with four blades each. In addition, nine fed-batch runs were performed in a 5-L New Brunswick Bioflo fermenter under the same conditions as those of the batch runs, with an initial volume of $3.5 \mathrm{~L}$ and a feed volume of $1.0 \mathrm{~L}$, using an exponential feed rate (Pamboukian, 2003; Pamboukian and Facciotti, 2004a).

\section{Inoculum Preparation}

The inoculum for the fermenter runs was prepared in a New Brunswick rotary shaker at 200 $\mathrm{rev} / \mathrm{min}$ and $30^{\circ} \mathrm{C}$ in two steps: first during $16 \mathrm{~h}$ and then during $24 \mathrm{~h}$ (Guimarães, 2000).

\section{Methodology}

Samples collected periodically from the fermenter were evaluated for biomass, rheological properties and morphology.

Biomass (X) was evaluated after vacuum filtration and drying (Guimarães, 2000).

Rheological properties (consistency index (K) and flow behavior index (n)) were determined offline, employing a digital Brookfield Rheometer (LVDV III) with a small sample adapter, connected to a microcomputer running Rheocalc software (Pamboukian, 2003). The spindle speedy was varied between 1 and 150 r.p.m. The spindles used were: ULAdapter (shear rate in the range between 0 and $322 \mathrm{~s}^{-1}$, which corresponds to an apparent viscosity between 1.0 and $5000 \mathrm{cP}$ ), SSA-18 (shear rate in the range between 0 and $330 \mathrm{~s}^{-1}$, which corresponds to an apparent viscosity between 1.3 and $30000 \mathrm{cP}$ ) and SSA-31 (shear rate in the range between 0 and $85 \mathrm{~s}^{-1}$, which corresponds to an apparent viscosity between 12 and $30000 \mathrm{cP}$ ).

Morphology was evaluated by image analysis, using a criterion for classification of the microorganism in four morphological classes (pellets, clumps, branched filaments and unbranched filaments, as indicated in Figure 1, similarly to other works in literature (Yang et al., 1996; Paul and Thomas, 1998), using a LEICA Q550IW Image Analyser attached to a LEICA DM/LS optical microscope (Pamboukian et al., 2002). The images were acquired with a SONY DXC-950P CCD camera. The microscope images were recorded with a resolution of $764 \times 574$ pixels and 256 grey values. The grey image was corrected using erosion and dilation before binarization. The image was then segmented by two thresholds to obtain a binary 
image. In the segmentation process, pixels that have a grey scale between the two thresholds are picked out and the others are eliminated to form the binary image (Paul and Thomas, 1998). After binarization, the binary image was corrected using erosion, dilation, skeletonization and pruning. Skeletonization and pruning were useful to obtain the number of tips of the hyphal elements. Samples from the culture broth were diluted 5- to 100-fold with distilled water. A $20 \mu \mathrm{L}$ aliquot of the diluted sample was pipetted onto a slide glass, dried and fixed over a Bunsen flame, and stained with methylene blue $(0.3 \mathrm{~g}$ methylene blue, $30 \mathrm{~mL} 95 \%$ ethyl alcohol, in 100 $\mathrm{mL}$ distilled water) (Yang et al., 1996). For each sample, a minimum of 100 objects was measured and the percentage of each morphological class, in terms of projected area, was determined (Pamboukian et al., 2002) as well as the average clump dimension (D), which represented the major morphological class in all runs. Average clump dimension was defined as the average of the dimensions of the clumps in eight different directions (ferets).

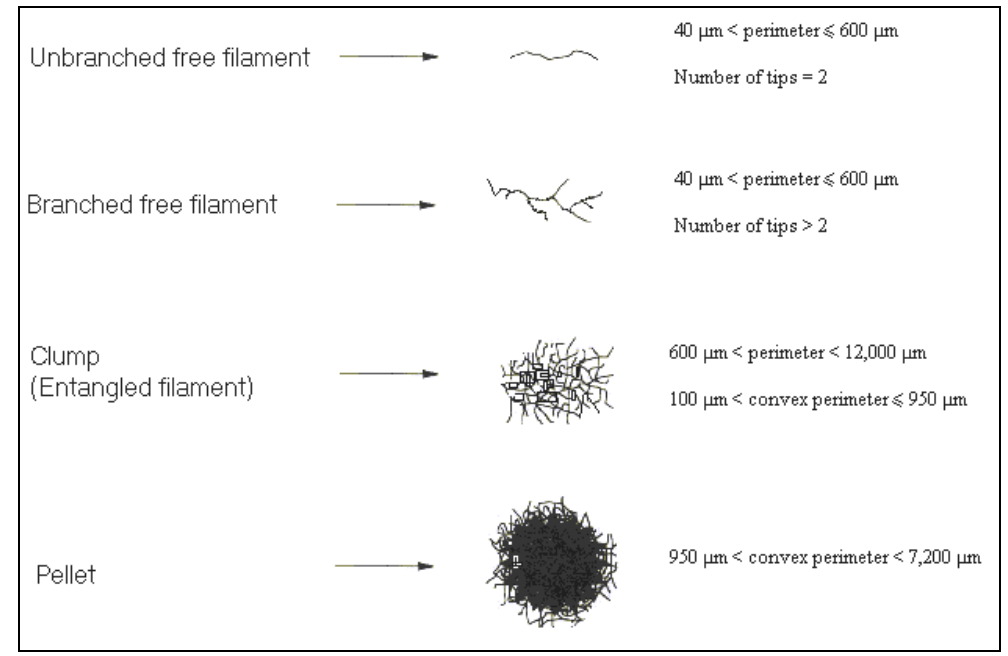

Figure 1: Morphological classes of Streptomyces olindensis grown in submerged cultures and the main characteristics of each class (Pamboukian et al., 2002).

\section{RESULTS AND DISCUSSION}

Figure 2 shows a typical behavior obtained for biomass $(\mathrm{X})$, consistency index $(\mathrm{K})$ and flow behavior index (n) in a batch cultivation of Streptomyces olindensis. The error bars represent the standard deviation in the samples. In Figure 2, it can be observed that biomass increased during the first $20 \mathrm{~h}$ of cultivation, after which a stationary phase was reached. Similar behavior can be observed in the consistency index $(\mathrm{K})$ profile, which reached a maximum of 7.3 dyne. $\mathrm{s}^{\mathrm{n}} / \mathrm{cm}^{2}$ at about $40 \mathrm{~h}$ of cultivation. For the flow behavior index (n), the value obtained was near 1.0, in the beginning of cultivations, showing Newtonian behavior at the beginning of fermentation. In the course of fermentation, the flow behavior index decreased to a minimum value about 0.25 , showing pseudoplastic behavior, characteristic of filamentous microorganisms cultivations, as noted by many authors (Allen and Robinson, 1990; Ruohang and Webb, 1995, Pamboukian et al., 1998).
Figure 3 shows the evolution of the four morphological classes (pellets, clumps, branched and unbranched hyphae) during a typical batch run, determined by image analysis. During the first $20 \mathrm{~h}$ of cultivation, the percentage of pellets decreased in the fermenter with a concomitant increase in clumps and free hyphae (both branched and unbranched filaments), probably as a consequence of shear stress and physiological changes. The increase in the consistency index (K), in the beginning of fermentation, may be correlated with the decrease in pellet percentage and with the increase in clump and free hyphae percentage, since the growth in the form of pellets causes the suspension to be less viscous. Even after $20 \mathrm{~h}$ of cultivation, a slight increase in the consistency index ocurred, probably due to the increase in the free hyphae percentage. At the end of fermentation, cell growth was mainly in the form of clumps (about $80 \%$ ) and branched filaments (about $12 \%)$ with no pellets in the culture medium. Since growth in the form of pellets causes the cell suspension to be less viscous (Pamboukian et al., 
1998), the predominance of either clumps or free filaments causes the suspension to be more viscous, with a higher consistency index and pseudoplastic behavior, as described above.

Similar behavior could be observed in fed-batch runs, as illustrated in figures 4 and 5. Biomass concentration increased up to $26 \mathrm{~h}$ of cultivation, reaching a maximum value of about $6.8 \mathrm{~g} / \mathrm{L}, 42 \%$ higher than the batch run presented earlier. Similarly, consistency index reached a maximum of about 17 dyne. $\mathrm{s}^{\mathrm{n}} / \mathrm{cm}^{2}$ at $32 \mathrm{~h}$ of cultivation, higher than the consistency index obtained in the batch run due to the higher cell concentration. The flow behavior index showed a profile similar to the one obtained in the batch run, as discussed previously.

The increase in the consistency index during fermentation can be attributed to both the increase in biomass and the morphology primarily in the form of clumps and free filaments (about $90 \%$ and $10 \%$, respectively). At the end of cultivation, a decrease in the consistency index can be observed, probably due to hyphal fragmentation and lysis.

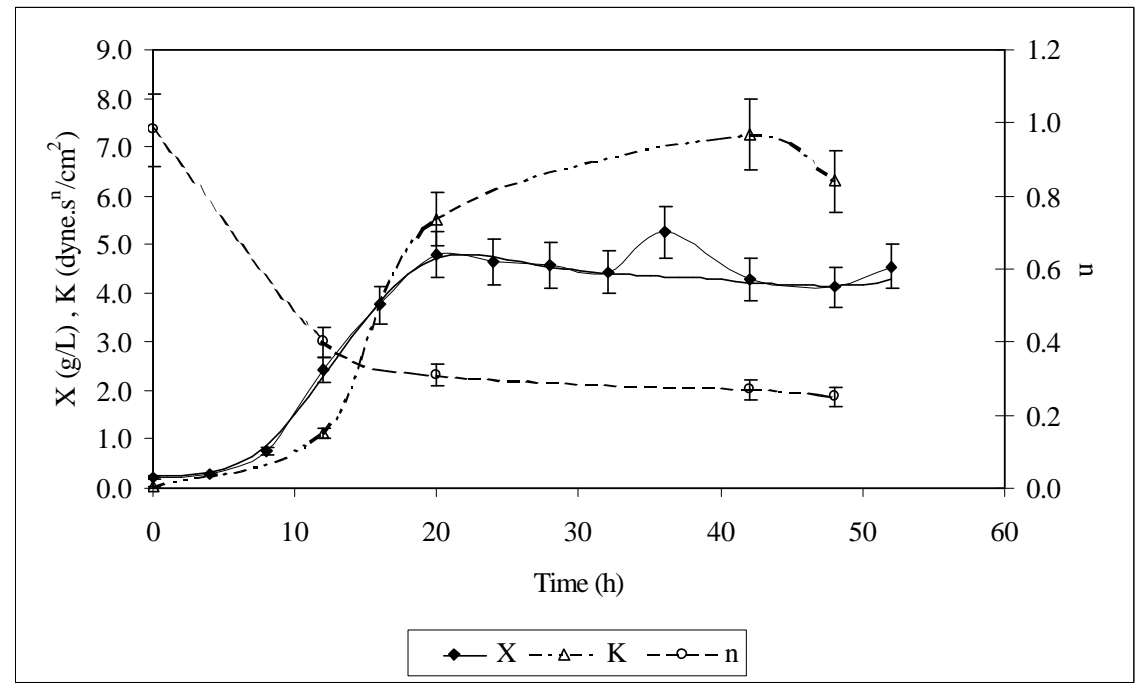

Figure 2: Biomass $(\mathrm{X})$, consistency index $(\mathrm{K})$ and flow behavior index $(\mathrm{n})$ during a typical batch cultivation of Streptomyces olindensis.

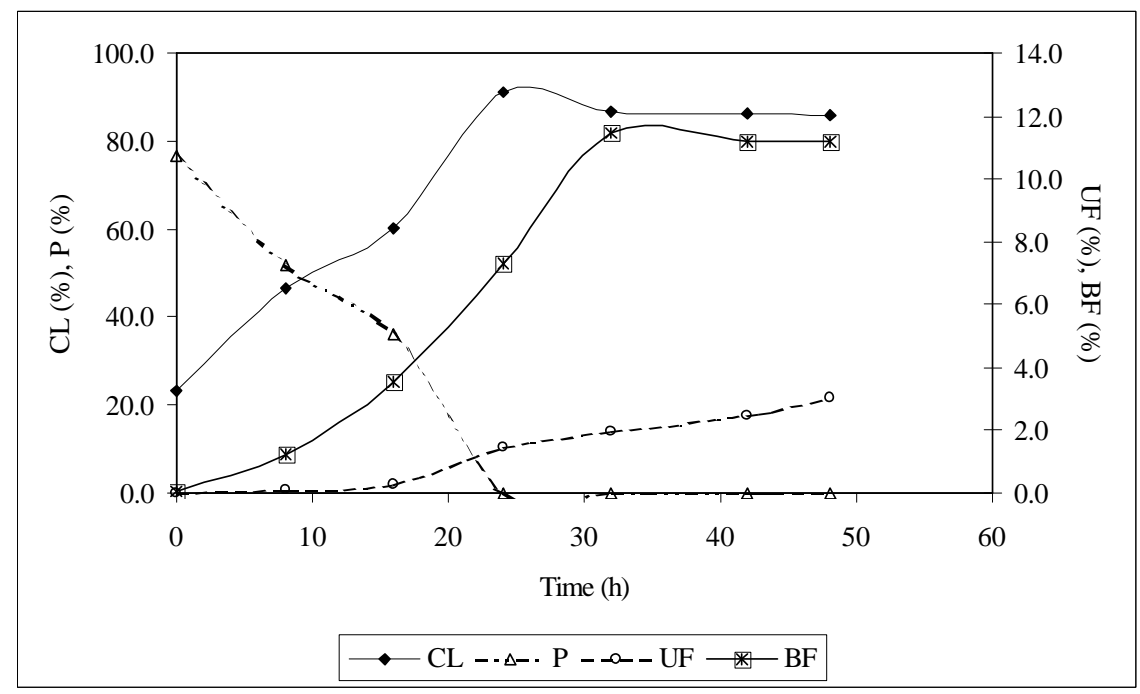

Figure 3: Percentage of pellets (P), clumps (CL), branched filaments (BF) and unbranched filaments (UF) during a typical batch cultivation of Streptomyces olindensis. 


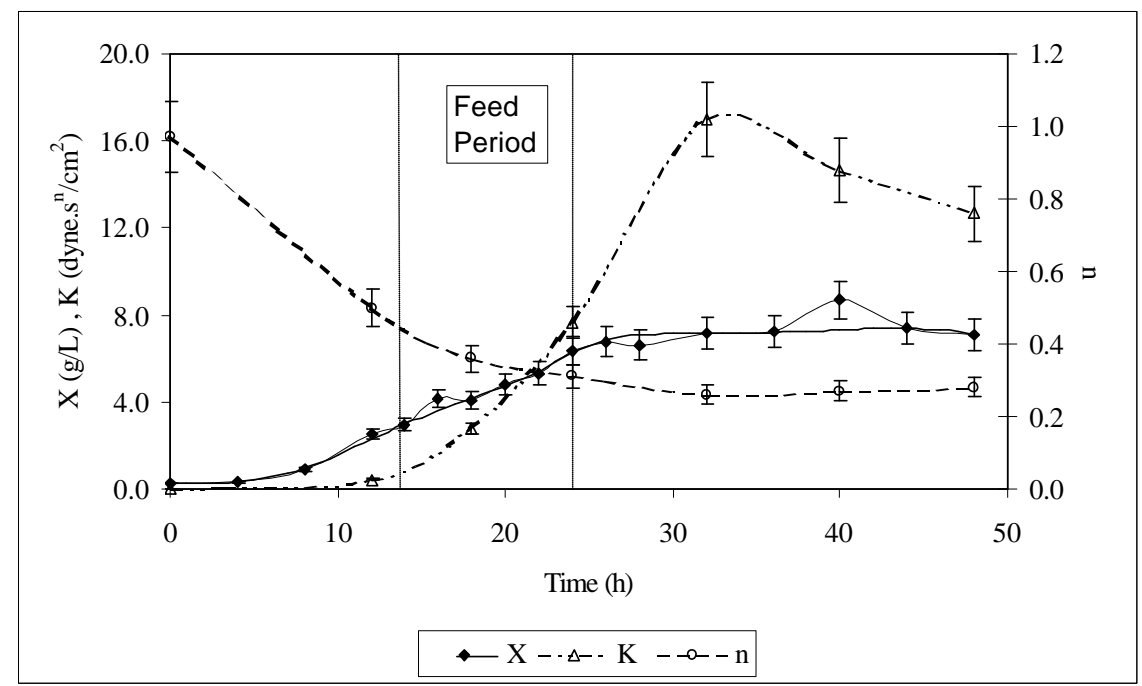

Figure 4: Biomass $(\mathrm{X})$, consistency index $(\mathrm{K})$ and flow behavior index (n) during a typical fed-batch cultivation of Streptomyces olindensis. Vertical lines represent the feed period.

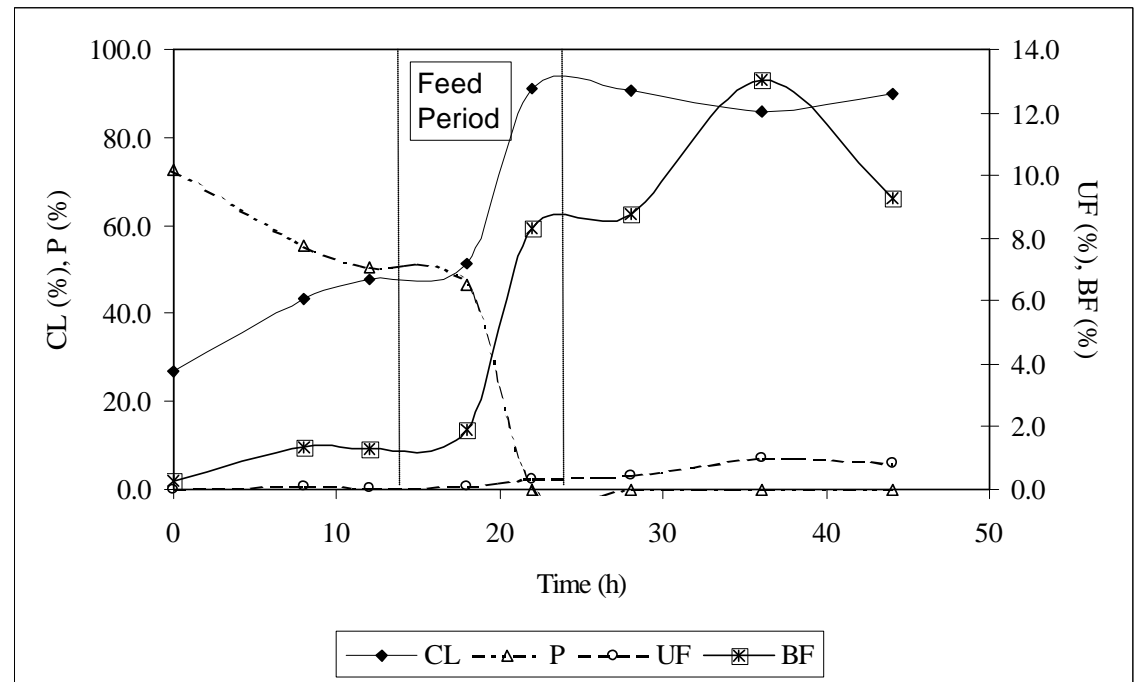

Figure 5: Percentage of pellets (P), clumps (CL), branched filaments (BF) and unbranched filaments (UF) during a typical fed-batch cultivation of Streptomyces olindensis. Vertical lines represent the feed period.

Figures 6 and 7 show the variation in the average clump dimension, during typical batch and fed-batch runs, respectively. Average clump dimension (D) was chosen to represent microorganism morphology, since clumps are the largest morphological class during most of cultivation (representing $80 \%$ to $90 \%$ of the total biomass at the end of cultivation). In the batch run, the average clump dimension of was about $180 \mu \mathrm{m}$ at the beginning of cultivation, decreasing up to $90 \mu \mathrm{m}$ during cultivation. In the fed-batch run, the average clump dimension was about $190 \mu \mathrm{m}$ at the beginning of cultivation, decreasing slightly to about $140 \mu \mathrm{m}$ during cultivation. This decrease in the average clump dimension can probably be attributed to shear stress and to physiological changes during cultivation.

Results of all runs (batch and fed-batch cultivations) were useful for obtaining mathematical correlations between biomass, morphology and rheological properties.

A first model, correlating the rheological properties with only the biomass concentration was tested, as shown in equations (1) and (2).

$$
\mathrm{K}=\mathrm{A}_{1} \cdot \mathrm{X}^{\mathrm{B} 1}\left(\text { dyne. } \mathrm{s}^{\mathrm{n}} / \mathrm{cm}^{2}\right)
$$




$$
\mathrm{n}=\mathrm{E}_{1} \cdot \mathrm{X}^{\mathrm{F} 1 \quad \text { (dimensionless) }}
$$

Figures 8 and 9 show the fit of equations (1) and (2) to the experimental data, which led to the following parameters:

$$
\mathrm{A}_{1}=0.21 \pm 0.01 \quad \mathrm{~B}_{1}=2.03 \pm 0.05
$$

$$
\mathrm{E}_{1}=0.58 \pm 0.01 \quad \mathrm{~F}_{1}=-0.39 \pm 0.01
$$

Thus, equations (1) and (2) can be expressed as:

$$
\mathrm{K}=0.21 \mathrm{X}^{2.03} \text { dyne. } \mathrm{s}^{\mathrm{n}} / \mathrm{cm}^{2} \quad\left(\mathrm{r}^{2}=0.95\right)
$$

$\mathrm{n}=0.58 \mathrm{X}^{-0.39}\left(\mathrm{r}^{2}=0.91\right)$

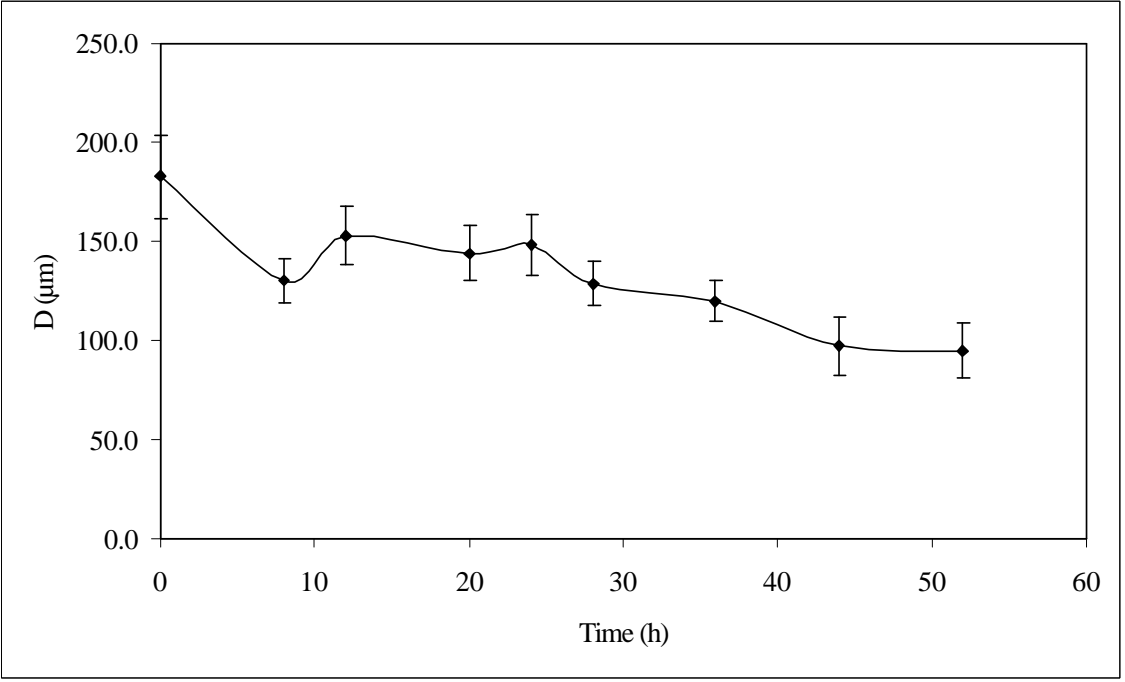

Figure 6: Average clump dimension (D) during a typical batch cultivation of Streptomyces olindensis.

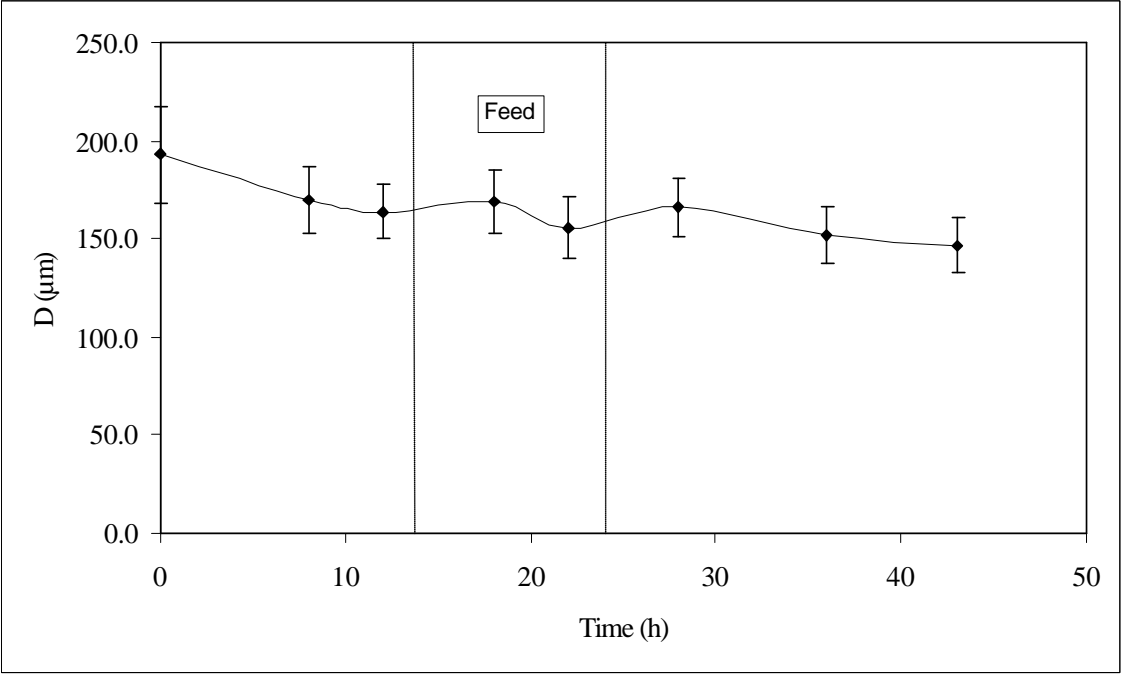

Figure 7: Average clump dimension (D) during a typical fed-batch cultivation of Streptomyces olindensis. Vertical lines represent the feed period. 


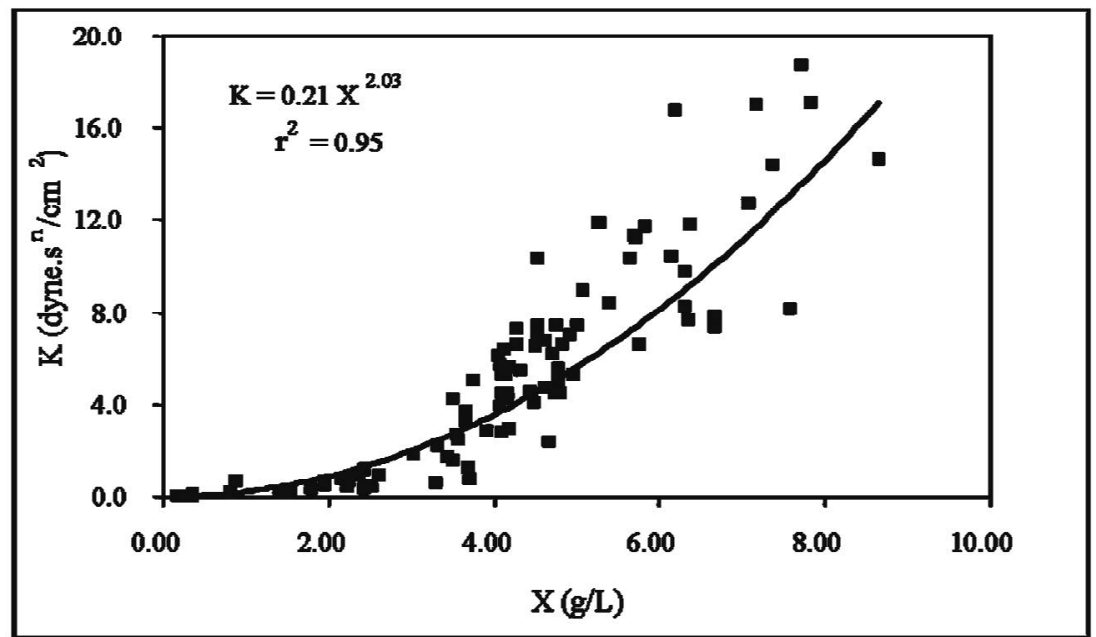

Figure 8: Correlation between consistency index $(\mathrm{K})$ and biomass $(\mathrm{X})$, during cultivations of Streptomyces olindensis in batch and fed-batch fermentations.

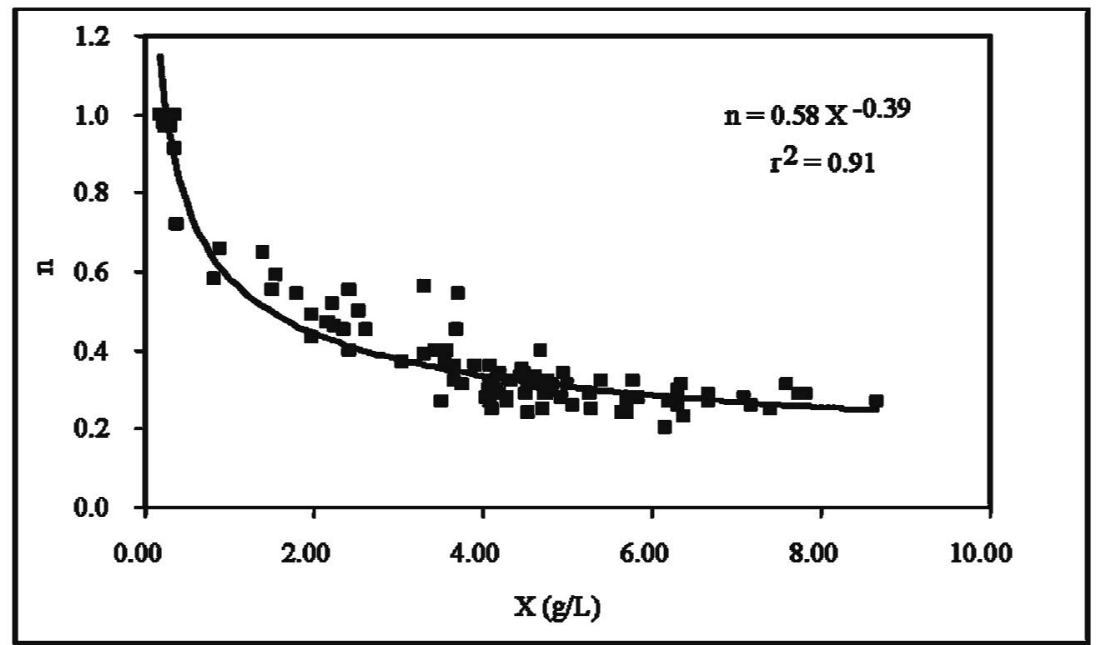

Figure 9: Correlation between flow behavior index (n) and biomass (X), during cultivations of Streptomyces olindensis in batch and fed-batch fermentations.

Similar correlation between $\mathrm{K}$ and $\mathrm{X}$ were obtained, in a work with Aspergillus awamori $(\mathrm{K}=$ $0.89 \mathrm{X}^{1.48}$ dyne. $\mathrm{s}^{\mathrm{n}} / \mathrm{cm}^{2}, \mathrm{r}^{2}=0.94$ ) (Queiroz et al.,1997), but the values of $\mathrm{K}$ were significantly higher in Aspergillus cultivations, because it is a filamentous fungus, with larger dimensions than Streptomyces olindensis (filamentous bacteria) (Allen and Robinson, 1990).

Further work was done in order to introduce morphological parameters into equations (1) and (2), so better results were obtained by introducing the average clump dimension (D) into the equations, as pointed out previously, leading to the following equations:

$$
\begin{aligned}
& \mathrm{K}=\mathrm{A}_{2} \cdot \mathrm{X}^{\mathrm{B}_{2}} \cdot \mathrm{D}^{\mathrm{C} 2} \text { (dyne. } \mathrm{s}^{\left.\mathrm{n} / \mathrm{cm}^{2}\right)} \\
& \mathrm{n}=\mathrm{E}_{2} \cdot \mathrm{X}^{\mathrm{F} 2} \cdot \mathrm{D}^{\mathrm{G} 2} \text { (dimensionless) }
\end{aligned}
$$

Adjusting equations (3) and (4) to the experimental data led to the following parameters:

$$
\begin{array}{ll}
\mathrm{A}_{2}=0.0043 \pm 0.0016 & \mathrm{~B}_{2}=2.05 \pm 0.05 \\
\mathrm{C}_{2}=0.82 \pm 0.42 & \\
\mathrm{E}_{2}=2.96 \pm 0.20 & \mathrm{~F}_{2}=-0.41 \pm 0.01 \\
\mathrm{G}_{2}=-0.32 \pm 0.10 &
\end{array}
$$

Thus, equations (3) and (4) can be expressed as:

$\mathrm{K}=0.0043 \mathrm{X}^{2.05} \mathrm{D}^{0.82}$ dyne. $\mathrm{s}^{\mathrm{n}} / \mathrm{cm}^{2}\left(\mathrm{r}^{2}=0.94\right)$

$\mathrm{n}=2.96 \mathrm{X}^{-0.41} \mathrm{D}^{-0.32} \quad\left(\mathrm{r}^{2}=0.91\right)$

These results showed that the two models presented similar regression coefficients $\left(\mathrm{r}^{2}\right)$. In 
addition, the values of $B_{1}$ and $B_{2}$, which represent the influence of biomass concentration on the consistency index in the models, were very similar (around 2.0). Similarly, the values of F1 and F2, which represent the influence of biomass concentration on the flow behavior index in the models, were similar (around -0.40), as obtained by other authors (Olsvik et al., 1993; Riley et al., 2000).

Figures 10 and 11 show a comparison between the experimental results and the results predicted by the two models (equations (1) and (3)), for the consistency index $(\mathrm{K})$. It can be observed that, in spite of a slightly lower regression coefficient, equation (3) represents the experimental data more accurately, what can be seen through both linear and angular coefficients of the straight line fitted, confirming thus, that the introduction of a morphological parameter into the consistency index model improved the prediction of the experimental data.

Similarly, Figures 12 and 13 show a comparison between the experimental results and the results predicted by the two models (equations (2) and (4)), for the flow behavior index (n). It can be observed that both models could be used to predict the experimental values of the flow behavior index with no significant difference. Thus, introduction of a morphological parameter in the model indicate that morphology has no influence on the flow behavior index.

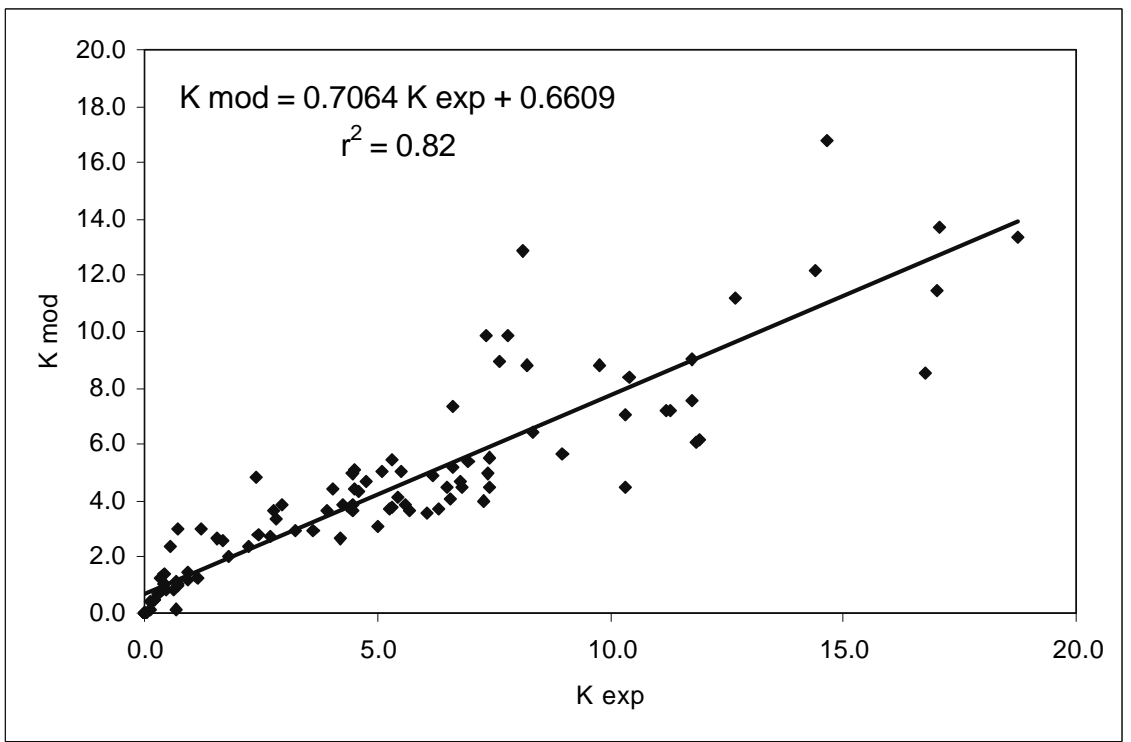

Figure 10: Comparison between the experimental values of the consistency index $\left(\mathrm{K}_{\exp }\right)$ and the values of the consistency index predicted by equation (1) $\left(\mathrm{K}_{\mathrm{mod}}\right)$.

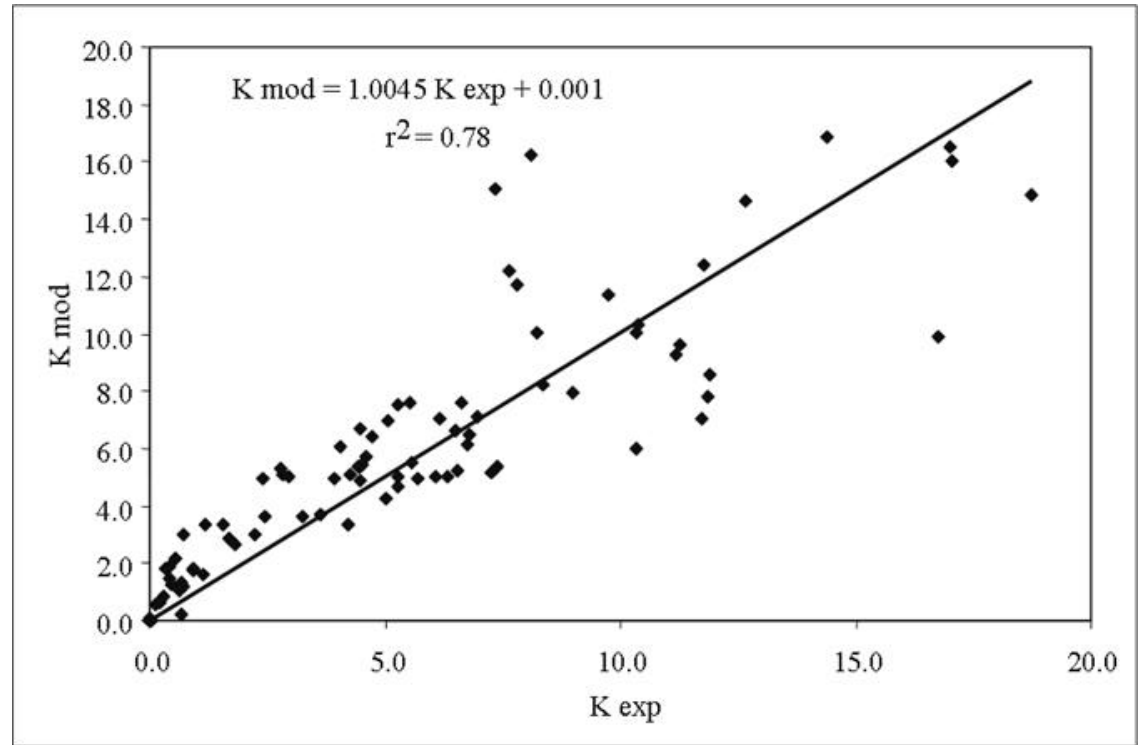

Figure 11: Comparison between the experimental values of the consistency index $\left(\mathrm{K}_{\exp }\right)$ and the values of the consistency index predicted by equation (3) $\left(\mathrm{K}_{\mathrm{mod}}\right)$. 


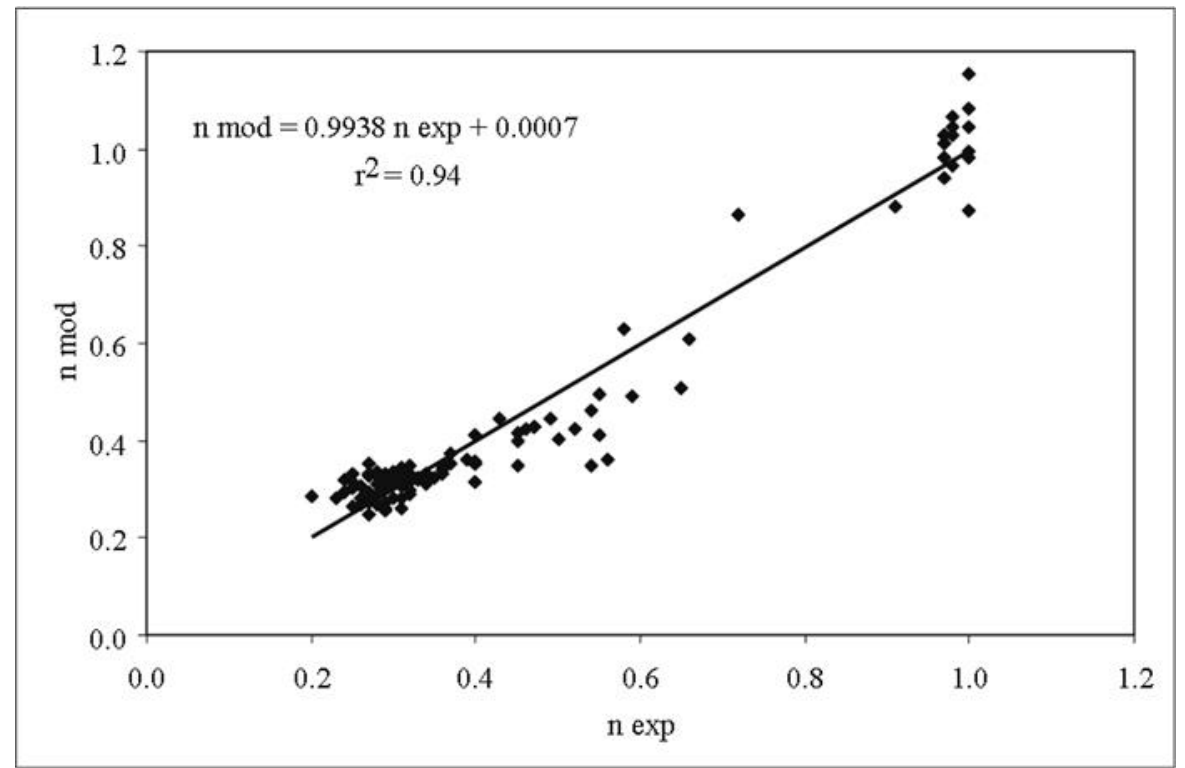

Figure 12: Comparison between the experimental values of the flow behavior index $\left(\mathrm{n}_{\exp }\right)$ and the values of the behavior index predicted by equation (2) $\left(\mathrm{n}_{\text {mod }}\right)$.

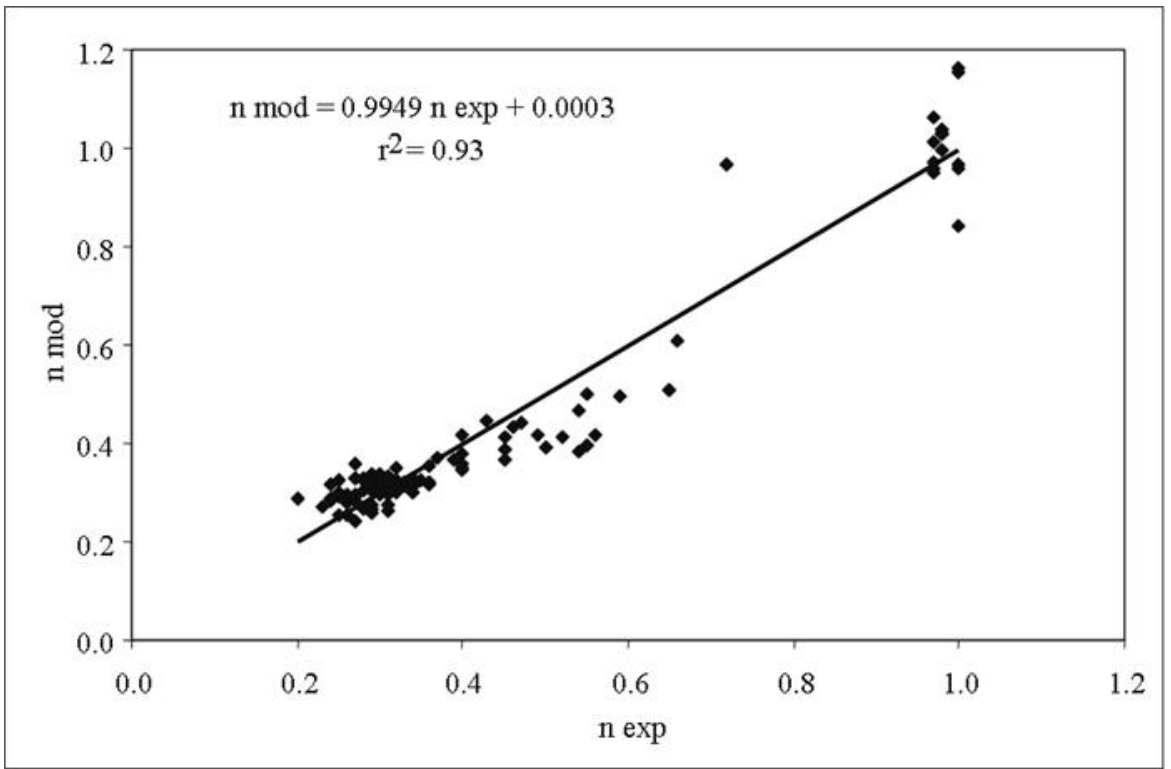

Figure 13: Comparison between the experimental values of the flow behavior index $\left(\mathrm{n}_{\exp }\right)$ and the values of the behavior index predicted by equation (4) $\left(n_{\text {mod }}\right)$.

\section{CONCLUSIONS}

Rheological properties of Streptomyces cultivations were shown to be dependent on the biomass concentration and morphological characteristics of the growing cells. A good fit was obtained between rheological properties, biomass concentration and average clump dimension, using results of fermentations in both batch and fed-batch cultivations. Incorporation of a morphological parameter (average clump dimension) produced better results in the prediction of the consistency index by the model, but did not influence the prediction of the flow behavior index.

\section{ACKNOWLEDGEMENT}

The authors would like to thank FAPESP (Fundação de Amparo à Pesquisa do Estado de São Paulo) for its financial support during this project. 


\section{NOMENCLATURE}

BF Percentage of branched

hyphae

CL Percentage of clumps

$\mathrm{D} \quad$ Average clump dimension

$\mathrm{K} \quad$ Consistency index

$\mathrm{K}_{\exp }$ Experimental value of the consistency index

$\mathrm{K}_{\text {mod }} \quad$ Value of the consistency index predicted by the model

n Flow behavior index

$\mathrm{n}_{\exp } \quad$ Experimental value of the flow behavior index

$\mathrm{n}_{\text {mod }} \quad$ Value of the flow behavior index predicted by the model

$P \quad$ Percentage of pellets

UF Percentage of unbranched hyphae

$\mathrm{X} \quad$ Biomass concentration

\section{REFERENCES}

Allen, D.G. and Robinson, C., Measurement of Rheological Properties of Filamentous Fermentation Broths, Chemical Engineering Science, 45, 37-48 (1990).

Badino Jr, A.C., Facciotti, M.C.R. and Schmidell, W., Estimation of the Rheology of Glucoamylase Fermentation Broth from the Biomass Concentration and Shear Conditions, Biotechnology Techniques, 13, 723-726 (1999).

Bieber, L.W., Silva Filho, A.A., Silva E.C., Mello, J.F. and Lyra, F.D.A., The Anthracyclinic Complex Retamycin, 1. Structure Determination of the Major Constituents, Journal of Natural Products, 52, 385-388 (1989).

Furlan, R.L., Obtenção e Estudo de Mutantes com Produção Alterada do Antibiótico Retamicina Sintetizado por Streptomyces olindensis DAUFPE 5622, M.Sc. Thesis, Instituto de Ciência Biomédicas da Universidade de São Paulo, São Paulo (1997).

Guimarães, L.M., Influência do Preparo do Inóculo e do $\mathrm{pH}$ na Produção do Antibiótico Retamicina por Streptomyces olindensis So20, M.Sc. Thesis, Escola Politécnica da Universidade de São Paulo, São Paulo (2000).

Olsvik, E., Tucker, K.G., Thomas, C.R. and Kristiansen, B., Correlation of Aspergillus niger Broth Rheological Properties with Biomass
Concentration and the Shape of Mycelial Aggregates, Biotechnology and Bioengineering, 42, 1046-1052 (1993).

Pamboukian, C.R.D., Produção do Antitumoral Retamicina por Streptomyces olindensis em Processos Descontínuos Alimentados e Contínuos, Ph. D. Thesis, Escola Politécnica da Universidade de São Paulo, São Paulo (2003).

Pamboukian, C.R.D. and Facciotti, M.C.R., Production of the Antitumoral Retamycin During Fed-batch Fermentations of Streptomyces olindensis, Applied Biochemistry and Biotecnology, 112, 111-121 (2004a).

Pamboukian, C.R.D. and Facciotti, M.C.R., Production of the Antitumoral Retamycin during Continuous Fermentation of Streptomyces olindensis, Process Biochemistry, 39, 2249-2255 (2004b).

Pamboukian C.R.D., Guimarães L.M. and Facciotti M.C.R., Applications of Image Analysis in the Characterization of Streptomyces olindensis in Submerged Culture, Brazilian Journal of Microbiology, 33, 17-21 (2002).

Pamboukian, C.R.D. and Facciotti, M.C.R., Correlation between Pellet Size and Glucoamylase Production in Submerged Cultures of Aspergillus awamori, Revista de Microbiologia, 29, 23-26 (1998).

Pamboukian, C.R.D., Facciotti, M.C.R. and Schmidell, W., Relationship between Morphology, Rheology and Glucoamylase Production by Aspergillus awamori in Submerged Cultures, Brazilian Journal of Chemical Engineering, 15, 256-272 (1998).

Paul, G.C. and Thomas, C.R., Characterization of Mycelial Morphology Using Image Analysis, Advances in.Biochemical Engineering/Biotechnology, 60, 1-59 (1998).

Queiroz M.C.R., Facciotti M.C.R. and Schmidell W., Rheological Changes of Aspergillus awamori Broth During Amyloglucosidase Production, Biotechnology Letters, 19, 167-170 (1997).

Riley G.L., Tucker K.G., Paul G.C. and Thomas C.R., Effect of Biomass Concentration and Mycelial Morphology on Fermentation Broth Rheology, Biotechnoogy and Bioengineering, 68, 160-172 (2000).

Ruohang W. and Webb C., Effect of Cell Concentration on the Rheology of Glucoamylase Fermentation Broth, Biotechnology Techniques, 9, 55-58 (1995).

Yang, Y.K., Morikawa, M., Shimizu, H., Shioya, S., Suga, K., Nihira, T. and Yamada, Y., Image Analysis of Mycelial Morphology in Virginiamycin Production by Batch Culture of Streptomyces virginiae, Journal of Fermentation and Bioengineering, 81, 7-12 (1996). 